\title{
EXPLOSIVES *
}

\author{
By Prof. G. I. Finch, M.B.E., F.R.S. \\ imperial College of Science and Technology
}

\section{NATURE of an Explosive}

A $\mathrm{N}$ explosive is a store of chemical energy in liquid or solid form which can be rapidly converted into heat and thence into mechanical energy. The explosive products must be gaseous, either wholly or in part, because the heat energy of solid or liquid products is not directly available for doing work by expansion. It is a popular fallacy that an explosive is an unusually rich store of energy. The fact is, however, that with sufficient air petrol is, weight for weight, capable of doing nearly eight times as much work as nitroglycerine, which is one of the most powerful of explosives; but nitroglycerine does its work much more swiftly, disrupting and pushing away its surroundings in a fraction of a second.

There are several ways in which chemical energy can be stored to form an explosive. For example, we can mix a combustible material like sugar with an oxygen-rich compound such as potassium chlorate. A far more perfect apposition of combustible and oxygen is secured, however, when both are suitably combined into a single chemical compound. But this combination is a peculiar one, in that the combustible and the oxygen are only loosely or indirectly associated in the molecule, usually through the intermediary of some relatively inert atom such as nitrogen, as, for example, in ammonium nitrate. This is, however, not the only way of storing up chemical energy to form an explosive compound. Any compound is a store of chemical energy if a rearrangement of its constituent atoms is possible which is attended by the evolution of heat; and if the rearrangement can occur swiftly with the formation of gaseous products, then the compound is an explosive. Thus the dissociation of acetylene into soot (solid carbon) and molecular hydrogen liberates heat, and acetylene has long been recognized as an explosive gas, particularly when compressed. We can, most conveniently, effect this compression chemically, that is, by making use of some of the chemical energy stored in acetylene. Thus the hydrogen of acetylene is easily replaced by metals such as copper, silver and mercury. The resulting compounds are solids, so that their chemical energy is concentrated into a far smaller volume than in acetylene gas itself. These acetylides are violent explosives, which decompose into soot and a highly

* From a lecture at the Royal Institution delivered on February 11. heated gas of metallic atoms. In this case it is the resolution of the acetylene triple bond into the single bonds of soot which is the source of the heat energy.

There are other kinds of atomic arrangements which can serve as stores of easily released chemical energy. For example, although the dilute hydrogen peroxide of commerce is harmless, the pure liquid compound is explosive and decomposes readily into steam and molecular oxygen. Pure ozone, especially in the liquid or solid state, is an even more violent explosive. In each case the removal of an oxygen atom from the molecule requires the expenditure of much energy, but this is more than balanced by the heat evolved by the subsequent union of two such atoms to form a molecule of oxygen. Another atomic grouping where, on explosion, the main source of heat energy is furnished by the combination of like atoms to the molecular state is the triazo, $-\mathrm{N}=\mathrm{N} \equiv \mathrm{N}$, group. Hydrazoic acid, $\mathrm{HN}_{3}$, is an explosive liquid which readily forms a series of explosive metallic salts, of which lead azide is much used in the explosives industry.

An example of a class of compound in which the heat energy liberated on explosion results partly from the union of a combustible with an oxygen atom and partly from the formation of a molecule from like atoms is furnished by the fulminates. These are metallic salts of fulminic acid, $\mathrm{H}-\mathrm{O}-\mathrm{N} \equiv \mathrm{C}$, of which the best known is mercury fulminate, $\mathrm{Hg}(\mathrm{ONC})_{2}$. On explosion, an atomic rearrangement takes place to yield as sole explosion products carbon monoxide, molecular nitrogen and mercury.

\section{Sensitiveness}

The sensitiveness of an explosive reflects its stability, being a measure of the energy required to dislocate the arrangement of the atoms in its constituent molecules to such an extent that they tend to relapse into a more stable configuration rather than to return into their original positions. It is difficult, however, to obtain an absolute measure of this 'least initiating energy', as it may be called, and in practice comparative tests must suffice. The results are sometimes conflicting; thus, nitroglycerine is less sensitive to a hammer blow, but more sensitive to heat than lead azide. Recent advances in our knowledge of crystal and 
molecular structure and of the nature of the chemical bond, seem to offer a fair prospect of a better understanding of the energy relationships involved in initiating the explosive process, at least in those compounds which are crystalline and of simple molecular structure, like, for example, the acetylides and the azides.

When an unconfined explosive is ignited by a flame, one is struck by the fact that, with certain few exceptions, explosives respond in one of two very different ways. Thus, match compositions, nitroglycerine, guncotton, blasting gelatine, cordite and gunpowder burn quietly, some more quickly than others, with flames of characteristic colour. Picric acid, trinitrotoluene and the aromatic nitrates in general burn sluggishly with a sooty flame. In striking contrast to this quiet burning is the behaviour of most of the acetylides, azides and the fulminates, which explode with great violence and set up intense shock waves when ignited. A closer examination reveals that this violent explosive process is preceded by a short period during which an initially slow rate of burning rapidly accelerates until the violently explosive stage is reached. In the case of burning, the energy needed to start decomposition in the hitherto unaffected portion of the explosive is handed on as heat from the burning zone to the adjacent unconsumed layer, which is thus ignited, and so on from layer to layer throughout the explosive. On the other hand, the succeeding violently explosive stage is due to the setting up, as the result of a _rapidly accelerating rate of burning, of a steep-fronted sound wave which travels through the explosive at a high uniform speed. The intensity of this wave is so great, approaching $150,000 \mathrm{kgm} . / \mathrm{cm} .{ }^{2}$, that the explosive at the wave front may momentarily be heated, by adiabatic compression, to a temperature of the order of $10,000^{\circ} \mathrm{C}$., so that the resulting explosion is propagated hand-in-hand with, and maintains the intensity of, the shock wave in its passage throughout the explosive. In traversing an inert medium, such as air, this intensity of course decreases rapidly; nevertheless, the shock wave may still be capable of effecting explosion, even though attenuated by passage through a considerable air gap.

\section{Detonants}

The process whereby explosion is effected by a shock wave is known as detonation. An explosive which, even when unconfined, burns rapidly to detonation may be called a detonant. The shock wave is usually known as the detonation wave. Its velocity lies between 3,000 and 9,000 metres per second, and is related to that of sound in the same medium; hence, each explosive has its own characteristic and constant rate of detonation. The detonants, of which lead azide and mercury fulminate are the best known representatives, play a vital part in the use of modern high explosives.

Ability to burn to detonation is not necessarily associated with a high degree of sensitiveness, nor is it evidence of high energy contents of the explosive, as is sometimes supposed. For example, both nitroglycerine and cordite are roughly four times as powerful as mercury fulminate or lead azide. The explanation lies rather in the nature of the explosion products of such detonants, which are for the most part unable to dissociate appreciably, so that the chemical energy is transformed into heat in a single step instead of relatively slowly, by a succession of stages.

\section{Propellants}

The large class of explosives which burn quietly when unconfined may be further subdivided into propellants and the so-called high explosives, according to their behaviour when ignited by flame in a strong enclosure. A propellant, like gunpowder or cordite, merely burns. If it is non-porous and uniform in texture, like cordite, the propellant continues to burn from layer to layer at much the same uniform rate as when unenclosed, while a porous substance, like gunpowder or a partially gelatinized smokeless powder, burns at a less uniform rate because the accumulating pressure forces hot gases into the pores and thus increases the rate of burning. Under similar conditions a high explosive, after a more or less prolonged period of burning of somewhat uncertain duration, eventually detonates.

As the name implies, the function of a propellant is to propel a selected object in a desired direction. It is essential that the pressure of the explosion gases on the projectile should neither vary abruptly nor stress the gun unduly. At the same time the maximum permissible pressure should be continually exerted on the projectile and, to avoid waste, the charge must be completely consumed before the projectile arrives at the muzzle. These demands are met by a proper choice of the area-toweight ratio of the propellant. For example, the cordite in a rifle cartridge consists of some fifty rods each about as thick as a darning needle. In a big gun, however, where the projectile takes much longer to arrive at the muzzle, the rods may exceed one inch in diameter.

An explosive which is liable to burn to detonation when confined as in a gun, is quite useless as a propellant. Should detonation occur, the gas pressure suddenly rises with such rapidity that the projectile cannot move fast enough to keep it within bounds, and the gun bursts and shatters 
into many fragments. Such disasters, or 'prematures' as they are sometimes called, were at one time by no means rare, and were due to the use of propellants of an unreliable nature. The possibility of a premature occurring with a modern high-class propellant like cordite is so remote as to be negligible. This does not imply that a propellant cannot be made to detonate like any high explosive, but rather that it will not do so under the conditions of its use in a gun.

\section{High Explosives}

In contrast to the propellants, the tasks which a high explosive has to perform are such as to require that its energy be made available in the shortest possible time. This can only be achieved by causing the explosive to detonate. If the gases were liberated slowly, as with a burning propellant, they would have time to open up weak places in the confining surroundings and then expand through these openings between the obstacles, instead of breaking up and flinging them away. For example, if the explosive charge in a shell were only to burn, then the slowly rising pressure would merely push out the fuse and the gases would escape through the fuse hole, leaving the shell intact. In the case of detonation, however, the gas pressure rises so quickly that there is no time for the inertia of the more easily removed obstacles to be overcome before the surroundings as a whole have been subjected to pressures which they cannot withstand. Hence when the shellfilling detonates, the shell walls are broken up into fragments which are pushed outwards with high velocity by the blast of the expanding gases of detonation. Similarly, a slab of guncotton, even though unenclosed and merely laid on a steel rail, will sever this on being detonated, but would leave it unharmed if the explosive were merely to burn.

When the manufacture of nitroglycerine had been established as a cheap commercial process, the problem of how to detonate it and thus unlock its energy to the best advantage became a pressing one. The solution was found in the discovery that the detonation wave in mercury fulminate, placed in contact with nitroglycerine, could set up in it a fresh detonation wave with a velocity characteristic of this medium.

Whilst the more sensitive high explosives, such as blasting gelatine and dry guncotton, can be detonated without fail in this manner, others, like moist guncotton and the aromatic nitro-compounds, especially when cast or highly compressed, are uncertain in their response to the effects of even relatively large amounts of detonant, being often merely broken up into fragments and scattered. The difficulty is overcome by interposing between the detonator and the main insensitive explosive a few grams of a high explosive which will respond with certainty to the action of the detonator, and then pass on its own detonation wave to the main body of the insensitive explosive. This intermediate explosive is generally known as the 'gaine.'

The choice of a high explosive is governed by the kind of work it will have to do, and by the treatment to which it is likely to be subjected before use. As shell fillings, only explosives which are highly insensitive to shock and friction can be used with safety; otherwise detonation may occur before the fuse acts, or even before the shell leaves the gun barrel. Also, the gaine explosive, and still more so the detonator contents, must be so packed and supported in the main body of the shell filling that they too can withstand with certainty the rough handling of being fired from the gun. Finally, when the filling does its work, the shell should break up into swiftly moving fragments of the most effective size, and not be merely split into a few large pieces or completely pulverized. If nearly all the chemical energy became available immediately on detonation, as is the case, for example, with lead azide, the shell would be broken up into powder and fragments too small for effective flight, and the explosive is said to be 'brisant' or shattering. On the other hand, if the chemical energy is transformed into heat by a succession of steps as, for example, where such easily dissociated molecules as steam and carbon dioxide form the bulk of the explosion products, the shell fragments are likely to be too large; an effect to which a low velocity of detonation may also indirectly contribute. Finally, in order that the fragments should move away with high velocity, or that the shell should do as much damage as possible on bursting after penetration into an obstacle, the explosive should have high chemical energy contents and yield only gaseous products. These requirements can best be met by mixing together two or more explosive compounds, a procedure which may have, among others, the advantage of enabling costs to be reduced. Amatol, a high explosive consisting of a mixture of trinitrotoluene and ammonium nitrate, was introduced as a shell filling during the War of 1914-18; it was cheap and proved remarkably successful.

The high explosives used for blasting in quarrying and mining can be sufficiently sensitive to respond to a detonator without the added complication of an intermediate gaine, because the treatment which they receive in the course of transport, handling, and in the final packing into the shothole, is mild compared with that which a shell filling has to withstand. Here again, the 
properties of the explosive must suit the work in hand. For example, in tunnelling through hard rock, a shattering and powerful explosive will serve best by breaking up the rock into small pieces easily handled for removal. On the other hand, for quarrying out large blocks of stone or in coal mining, where 'small stuff' represents waste, explosives are used which are comparatively slow in their action. Owing to the danger of coal dust and firedamp explosions, so called 'safety' explosives have been introduced for use in coal mining. These are slow-acting high explosives in which are incorporated substances like crystal soda which, by absorbing heat, prevent the temperature of the explosion flame from rising sufficiently to ignite coal-dust and methane-air mixtures.

\section{O B I T UAR IES}

\section{Prof. William Bulloch, F.R.S.}

$\mathrm{P}$ ROF. WILLIAM BULLOCH, emeritus professor of bacteriology in the University of London, whose death occurred on February 11, was a bacteriologist of world repute and the historian of bacteriology. $\mathrm{He}$ took up the science of bacteriology in its early days and lived to see it reach its modern importance. In these early days there were but few masters, but he made it his aim either to study with them or make himself familiar with their ideas and technique, and with Koch, Salomonsen, Metchnikoff, Ehrlich and Roux he maintained an intimate friendship.

William Bulloch was born in Aberdeen in August 1868 and studied at the University there, taking his M.B., C.M. in 1890 and afterwards studying in several centres of learning on the Continent (Leipzig, Paris and Vienna). He was a brilliant student and was awarded many academic prizes and honours. Among the more important appointments which he held were that of assistant professor of pathology, University College, London, wherehe came into contact with David Ferrier and Victor Horsley ; and bacteriologist at the Lister Institute, where he was associated with Lord Lister, of whom he became a life-long friend. In 1897 he was appointed bacteriologist to the London Hospital, to which he remained faithfully attached for the rest of his scientific career.

His great ability, his wide knowledge of his subject, and his integrity, soon established Bulloch as one of the foremost authorities on bacteriology in Great Britain, and for this reason he was invited to fulfil many important positions of trust. Thus he was chairman of the governors of the Lister Institute, an original member of the Medical Research Committee (Council), a member of the Government Committee on Foot and Mouth Disease, a member of the Committee of the Beit Memorial Trust, president of the Section of Pathology of the Royal Society of Medicine, honorary librarian to the Royal Society of Medicine for many years, and honorary fellow of this Society in 1940, honorary member of the Pathological Society of Great Britain and Treland, etc. He also gave many important lectures in connexion with bacteriology.

Bulloch added much to the knowledge of his subject, and the more important of his published works covered such subjects as tuberculosis, bacteriological filters, studies in pathology, hæmophilia (with Fildes) in the "Treasury of Human Inheritance", the sterilization of eatgut and diphtheria-its bacteriology, pathology and immunology, with others for the Medical Research Council.

I first met Bulloch some thirty-five years ago when a student. In the course of conversation I mentioned that I was about to go abroad to study, and he at once furnished me with the necessary introductions; the latter, as all friends of Bulloch know, acted as a magic charm to the portals of the great masters. Later, when I went to work in his Department at the London Hospital, I learned much of the man and his ideals. Bulloch was extremely conservative; in his own mind only the written word was authoritative, and us younger men he regarded somewhat as Bolsheviks in our views and methods. Thus some new procedure of technique we had devised or adopted would call forth the remark, "such methods are enough to make Pasteur and Koch turn in their graves". Yet in spite of this expression of doubt as to the success or usefulness of our investigations he would, a morning or two later when he came in for a friendly chat, present us with the latest literature on the subject of our research. The same interest in our progress was continued even when we had passed on from his Department. This generous disposal to us of his wide and accurate knowledge was in strong contradiction to his lack of interest in teaching medical students, which to him was of the nature of a necessary evil.

Perhaps Bulloch's outstanding characteristic was his highly developed critical faculty, at times devastating and even a little cruel when directed against imperfect or inaccurate work, only equalled by his intolerance of intrigue and advertisement. In his earlier days woe betide those who failed to come up to his standard, either in their writings or at a scientific meeting. But those who worked for him, even though his criticism was sometimes irritating, learned much that was to prove the foundation of their later successes.

Though brusque in manner, at home Bulloch was a genial and kindly host and liked to give play to his favourite hobby, the study of the frailties of the great men of his subject and of his immediate and humble associates. This gave him a fund of very amusing stories which he loved to recount with a clever mimicry, worthy of Coquelin himself, as a 